\title{
Specific Features of Fibrotic Lung Fibroblasts Highly Sensitive to Fibrotic Processes Mediated via TGF- $\beta$-ERK5 Interaction
}

\author{
Kotaro Kadoya ${ }^{a, b}$ Shinsaku Togo $o^{a, b}$ Miniwan Tulafu ${ }^{a, b} \quad$ Yukiko Nambaa,b \\ Moe Iwai ${ }^{a, b}$ Junko Watanabe ${ }^{a, b}$ Takahiro Okabe ${ }^{a, b}$ Jin Jin ${ }^{a, b, c}$ Yuzo Kodama ${ }^{a, b}$ \\ Hideya Kitamurad ${ }^{d}$ Takashi Ogura $^{d}$ Norikazu Kitamura ${ }^{\mathrm{e}}$ Kazuho Ikeo e,f \\ Tadayuki Takeda ${ }^{g}$ Naoto Kondog Kazuhisa Takahashia,b \\ aDivision of Respiratory Medicine, Juntendo University Faculty of Medicine \& Graduate School of \\ Medicine, Tokyo, Japan, ${ }^{b}$ Research Institute for Diseases of Old Age, Juntendo University Graduate \\ School of Medicine, Tokyo, Japan, 'Department of Respiratory and Critical Care Medicine, Beijing \\ Hospital, National Center of Gerontology, Beijing, China, dDepartment of Respiratory Medicine \\ Kanagawa Cardiovascular and Respiratory Center, Yokohama, Japan, ${ }^{e}$ Center for Information Biology, \\ National Institute of Genetics, Mishima, Japan, 'Department of Genetics, SOKENDAl, Mishima, Japan,

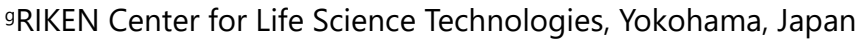

\section{Key Words}

Extracellular-signal-regulated kinase 5 (ERK5) - Fibulin-5 - Lung fibroblast - Smad • Transforming growth factor- $\beta 1$ (TGF- $\beta 1$ )

\begin{abstract}
Background/Aims: Lung fibrosis is associated with lung tissue contraction due to abnormal accumulation of myofibroblasts, which aggressively promote the fibrotic process. Transforming growth factor (TGF)- $\beta$ signaling in fibroblasts promotes extracellular matrix (ECM) synthesis and fibroblast migration and differentiation into myofibroblasts. Inhibition of extracellular signal-regulated kinase (ERK) 5 blocks lung fibroblast activation by suppressing TGF- $\beta$ signaling. Here, we examined the effects of an ERK5 inhibitor on TGF- $\beta 1$-induced fibrosis in lung fibroblasts. Methods: The effects of ERK5 inhibition following TGF- $\beta 1$ exposure were evaluated in lung fibroblasts isolated from fibrotic human lung tissues. Fibroblast-mediated collagen gel contraction and fibroblast migration towards fibronectin were assessed. Phenotypic differences in fibrotic fibroblasts were examined using the cap analysis gene expression method for genome-wide quantification of promoter activity. Results: TGF- $\beta 1$ stimulated contraction of collagen gels, fibroblast migration, and $\alpha$-smooth muscle actin and fibronectin expression, and Smad3 phosphorylation were increased in fibrotic fibroblasts
\end{abstract}




\section{Cellular Physiology Cell Physiol Biochem 2019;52:822-837

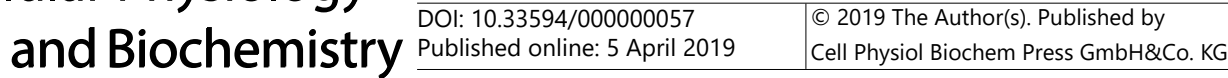 \\ Kadoya et al.: ERK5 Blockade Attenuates Lung Fibroblast Fibrotic Response}

as compared to normal lung fibroblasts. Treatment with the ERK5 inhibitor blocked these responses to a greater extent in fibroblasts from patients with usual interstitial pneumonia as compared to nonspecific interstitial pneumonia, independent of bone morphogenetic protein/Smad1 regulation. Moreover, 223 genes including fibulin-5 - which is involved in the TGF- $\beta 1$-ERK5 signaling network - were upregulated in fibrotic fibroblasts, and ECM regulation was found to be enriched in the Reactome analysis. Conclusion: ERK5 inhibition attenuated the high sensitivity of fibrotic fibroblasts to TGF- $31 / \mathrm{Smad} 3$ signaling. Thus, the ERK5 pathway components and fibulin-5 are potential therapeutic targets to prevent lung fibrosis progression.

(C) 2019 The Author(s). Published by Cell Physiol Biochem Press GmbH\&Co. KG

\section{Introduction}

Pulmonary fibrosis is characterized by a reduction in lung volume, resulting in a progressive loss of pulmonary function [1]. One major fibrotic process is lung tissue contraction, which leads to abnormal accumulation of myofibroblasts that exhibit greater contractility than normal fibroblasts, along with excessive deposition of extracellular matrix (ECM) [2]. Transforming growth factor (TGF)- $\beta$ is an important profibrotic growth factor that accelerates pulmonary fibrosis [3] and induces myofibroblast differentiation by increasing the expression of $\alpha$-smooth muscle actin ( $\alpha$-SMA), a contractile stress fiber. It also stimulates fibronectin release, resulting in the accumulation of lung fibroblasts at the site of fibrosis [47]. Bone morphogenetic proteins (BMPs) are structurally and functionally related proteins belonging to the TGF- $\beta$ superfamily of ligands. Maintaining a balance between TGF- $\beta$ and BMP signaling is critical for controlling fibrosis [8]. In particular, BMP-3 and -4 suppressed lung fibroblast proliferation and lung fibrosis progression in a bleomycin-induced lung fibrosis model [9-10]. However, it is not known how TGF- $\beta$ and BMP signaling affect lung fibroblasts derived from fibrotic lungs.

The extracellular-signal-regulated kinase (ERK)5, a member of the mitogen-activated protein kinase (MAPK) family, is stimulated by TGF- $\beta$. BIX02189, a pharmacological inhibitor of MAPK kinase 5/ERK5, blocked TGF- $\beta$ signaling and subsequent profibrogenic responses in a bleomycin-induced lung fibrosis model [11]. We previously demonstrated that BIX02189 attenuates acetylcholine and TGF- $\beta 1$-mediated ERK5 signaling, reducing the contractility of lung fibroblasts present in clinical samples from patients with chronic obstructive pulmonary disease (COPD), which suggests prevention of airway remodeling [12].

In this study, we first investigated whether inhibiting TGF- $\beta 1$ and ERK5 altered the bioactivity of lung fibroblasts isolated from patients with different subtypes of lung fibrosis. We then examined the phenotypic differences in fibrotic vs. normal fibroblasts by cap-analysis gene expression (CAGE) to identify potential mediators of lung fibroblast-mediated fibrosis. We speculated that TGF- $\beta 1$-mediated BMP regulation may be affected by ERK5 blocking. Finally, we explored whether clinicopathological information from multidisciplinary diagnoses correlated with the results obtained in the lung fibroblast bioactivity assays.

\section{Materials and Methods}

\section{Materials}

Native type I rat tail tendon collagen was extracted from rat tail tendons according to a previously published method [13]. Dulbecco's Modified Eagle's Medium (DMEM) was purchased from Wako Pure Chemical Industries (Osaka, Japan); fetal calf serum (FCS) from Sigma-Aldrich (St. Louis, MO, USA); transforming growth factor (TGF)- $\beta 1$ and bone morphogenetic protein (BMP)- 4 from R\&D Systems (Minneapolis, MN, USA); BMP-3 from Peprotech (Rocky Hill, NJ, USA); and the extracellular signal-regulated kinase (ERK)5 inhibitor BIX02189 from Selleckchem (Houston, TX, USA). 


\section{Cellular Physiology Cell Physiol Biochem 2019;52:822-837 \begin{tabular}{ll|l} 
and Bioch $10.33594 / 000000057$ & ( ) 2019 The Author(s). Published by \\
Cell Physiol Biochem Press GmbH\&Co. KG
\end{tabular} \\ Kadoya et al.: ERK5 Blockade Attenuates Lung Fibroblast Fibrotic Response}

Cell culture
Human fetal lung
fibroblasts (HFL1,
catalog no. CCL-153)
were purchased from the
American Type Culture
Collection (Manassas,

VA, USA). Primary lung fibroblasts were isolated from surgical lung specimens as previously described [14]. Briefly, for normal control lung fibroblasts, portions of lung parenchymal tissue as distal as possible from any tumor were obtained from patients who underwent lung cancer resection. For lung fibrotic fibroblasts, lung parenchymal tissue was isolated from the honeycomb-like fibrotic tissue. Lung fibroblasts from 24 patients, including 12 subjects with lung fibrosis according to a definitive final diagnosis by a multidisciplinary team recognized as the gold standard [15] and 12 control subjects without clinical airway symptoms or lung functional abnormalities were used for the experiments (Table 1). Further details are available in the online data supplement.

\section{Collagen gel contraction assay}

Collagen gels were prepared according to a previously described method [16], with some modifications. The ability of fibroblasts to contract the floating gels was evaluated by quantifying the gel area daily using a LAS4000 image analyzer (GE Healthcare Bio-Science AB, Uppsala, Sweden). Data are expressed as the gel area percentage compared to the original gel size.

\section{Chemotaxis assay}

Cell migration was assessed using a Boyden blindwell chamber (Neuroprobe, Gaithersburg, MD) as previously described [4-7]. Fibroblasts treated with TGF- $\beta 1$ and/or BMP-3/-4 in the presence or absence of BIX02189 were added to the wells of the upper chamber, while fibronectin was added to the wells of the lower chamber as a chemoattractant. Chemotaxis was assessed by counting the number of migrated cells in five high-power fields, including one in the center and one in each quadrant. Wells with serum-free Dulbecco's Modified Eagle's Medium served as negative controls.

\section{Fibronectin release measurements}

Fibronectin production from lung fibroblasts was determined using the human fibronectin immunoassay (R\&D Systems; Minneapolis, MN, USA) according to the manufacturer's instructions. Further details are available in the online data supplement.

\section{Western blotting}

Immunoblotting was performed using cell lysates with or without $10 \mathrm{pM}$ TGF- $\beta 1$ treatment in the presence or absence of BIX02189 for 8 or $24 \mathrm{~h}$. Detailed information on primary antibodies is available in the online data supplement.

\section{Small interfering RNA (siRNA)-mediated knockdown assays}

HFL-1 human fetal lung fibroblasts were transiently transfected with ERK5 siRNA using Lipofectamine 2000 reagent (Invitrogen by Life Technologies, USA) following the manufacturer's instructions. Further details are available in the online data supplement. 


\section{Cellular Physiology Cell Physiol Biochem 2019;52:822-837 \begin{tabular}{c|c|c|c|}
\hline DOl: 10.33594/000000057 & 2019 The Author(s). Published by \\
and Biochemistry & Publishod
\end{tabular} \\ \begin{tabular}{lll} 
Published online: 5 April 2019 & Cell Physiol Biochem Press GmbH\&Co. KG \\
\hline
\end{tabular} \\ Kadoya et al.: ERK5 Blockade Attenuates Lung Fibroblast Fibrotic Response}

\section{CAGE analysis}

CAGE libraries were prepared from purified RNA samples as previously described [17]. Briefly, total RNA was pretreated with PolyA polymerase in the presence of 3'-dATP to block the diol residue at the RNA 3'-end. First strand cDNA was synthesized from $5 \mu \mathrm{g}$ total RNA with an N6+3 base anchor primer by reverse transcription using SuperScript III (Thermo Fisher Scientific, Waltham, MA, USA). The diols in the cap structure of the ribose sugar were oxidized with $\mathrm{NaIO}_{4}$ on ice shielded from light, and then biotinylated using biotin hydrazide dissolved in dimethylsulfoxide. Single-stranded RNA was digested with RNase I (Promega, Fitchburg, WI, USA), and biotinylated RNA/cDNA was captured on the surface of streptavidinconjugated Dynabeads M-270 (Thermo Fisher Scientific). The cDNA was released by heat denaturation and purified by RNase I and RNase H digestion, followed by purification with AMPure XP beads (Beckman Coulter, Brea, CA, USA). The purified single-stranded cDNA was subjected to adaptor ligation at both ends, and second-strand cDNA synthesis was performed using DeepVent (exo-) DNA polymerase (New England Biolabs, Tokyo, Japan). The 8-plex CAGE library was sequenced by 50-base single-read sequencing in one lane of a flow cell on an Illumina HiSeq 2500 sequencer (Illumina, San Diego, CA, USA). The quality of CAGE reads was verified with FastQC v.0.11.2 (Babraham Bioinformatics, Babraham Institute, Cambridge, UK), and the reads were mapped to the reference human genome (hg38) using TopHat2 [18]. Based on the mapping results, transcription was quantified according to annotated genes in the hg38 human genome and compared between fibrotic and control lung fibroblasts using Cuffdiff2 [19]. All analyses were performed on Maser [20] implementing the analysis pipelines. A pathway enrichment analysis was performed for upand downregulated differentially expressed genes (DEGs; for statistics, see next subsection) in fibrotic lung fibroblasts using the Reactome database [21] (version V62). To determine whether DEGs belonged to an enriched pathway that could be linked to TGF- $\beta 1$ or ERK5, protein interaction networks were constructed with VaProS [22] using the "Via Path Search" function. We used Cytoscape 3.6.1 [23] to visualize these networks.

\section{Statistical analysis}

Results are expressed as the mean \pm SEM. Grouped data were evaluated by one-way analysis of variance (ANOVA) with Bonferroni correction. Comparisons between control and fibrotic lung fibroblasts were performed with the unpaired, two-tailed Mann-Whitney $U$ test. The Wilcoxon test was used for experiments where paired samples within a group were available. For these comparisons, each subject was considered as an individual data point. $\mathrm{P}$ values $<0.05$ were considered significant. Data were analyzed using Prism 6 software (GraphPad Inc., San Diego, CA, USA). For CAGE reads, the Cuffdiff2-generated P value was used to assess differential gene expression, and the $\mathrm{Q}$ value (false discovery rate, FDR) was applied to multiple comparisons according to the Benjamini-Hochberg procedure [24]. Differentially Expressed Genes (DEGs) were identified using a 0.05 threshold for the $Q$ value. For pathway enrichment analysis, the probability of observed overlaps between query DEGs and each pathway was calculated from the binomial distribution; FDRs were then estimated from the $\mathrm{P}$ values using the Benjamini-Hochberg procedure. Pathways that fulfilled the following two criteria were identified as enriched: 1) two or more DEGs were found in the pathway, 2) FDR $<0.05$.

\section{Results}

\section{Clinical and demographic features}

The clinical and demographic features of the subjects are presented in Table 1 . The two groups were similar regarding age, smoking status, and gender. However, they differed significantly in lung function; as expected, subjects with lung fibrosis had a lower percent forced vital capacity (\% FVC). A histological examination revealed that six of the 12 lung fibrosis subjects not receiving medication showed nonspecific interstitial pneumonia (NSIP), while the other six showed usual interstitial pneumonia (UIP), including three with idiopathic pulmonary fibrosis (IPF) and three with chronic hypersensitivity pneumonitis. 


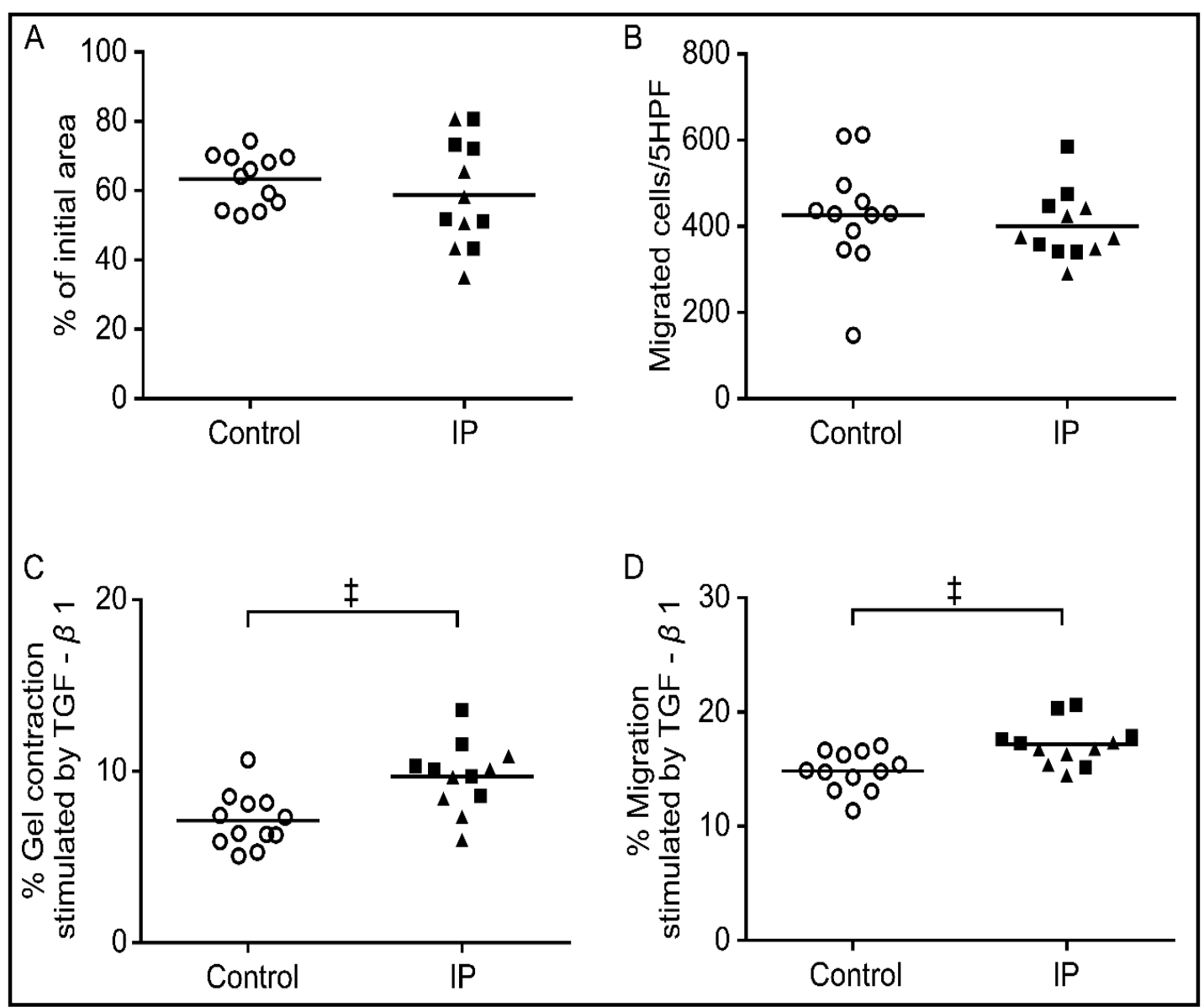

Fig. 1. Functional assays with control and lung fibrotic (interstitial pneumonia, IP) fibroblasts. (A) Contraction of three-dimensional collagen gels. Fibroblasts were cultured and cast into three-dimensional collagen gels that were maintained in suspension, with gel size measured daily. The vertical axis shows the gel size after 3 days of contraction, expressed as a percentage of the original size. (B) Chemotaxis. Fibroblasts were grown in a monolayer culture, trypsinized, and their chemotactic activity towards fibronectin $(20 \mu \mathrm{g} /$ $\mathrm{ml}$ ) was assessed. The vertical axis shows the number of migrated cells per five high-power fields (5HPF). (C) Effect of TGF- $\beta 1$ on gel contraction. The vertical axis shows the ratio of the size of TGF- $\beta 1$-stimulated gels to that of untreated gels on day 3. (D) Effect of TGF- $\beta 1$ on chemotaxis. The vertical axis shows the ratio of the number of migrated cells in response to TGF- $\beta 1$ treatment to that of migrated cells without treatment. Responses of fibroblasts from control and IP subjects to TGF- $\beta 1$ in the gel contraction and chemotaxis assays were assessed as described in the Materials and Methods. Closed triangles and squares indicate lung fibrosis subjects with histological nonspecific interstitial pneumonia and usual interstitial pneumonia patterns, respectively. Each symbol represents one patient. The values represent the mean \pm SEM of at least three independent experiments. ${ }^{\ddagger} \mathrm{P}<0.005$.

\section{Response to TGF- $\beta 1$}

Two phenotypes were examined in patients with lung fibrosis and control subjects; the ability of fibroblasts to contract three-dimensional collagen gels and their chemotaxis towards fibronectin. At the end of the incubation period, there were no differences in cell viability in the gels in either group, as assessed by the 3-(4, 5-dimethylthiazol-2-yl)-2, 5-diphenyltetrazolium bromide assay (data not shown), and no differences were observed between fibroblasts from subjects with lung fibrosis and those from control subjects at baseline (Fig. 1A, B). Since the phenotype at baseline was identical, we assessed the response to TGF- $\beta 1$, which induces fibrotic features in vitro. Exposure to exogenous TGF- $\beta 1$ enhanced its ability to stimulate the contraction of collagen gels (\% gel contraction stimulated by 


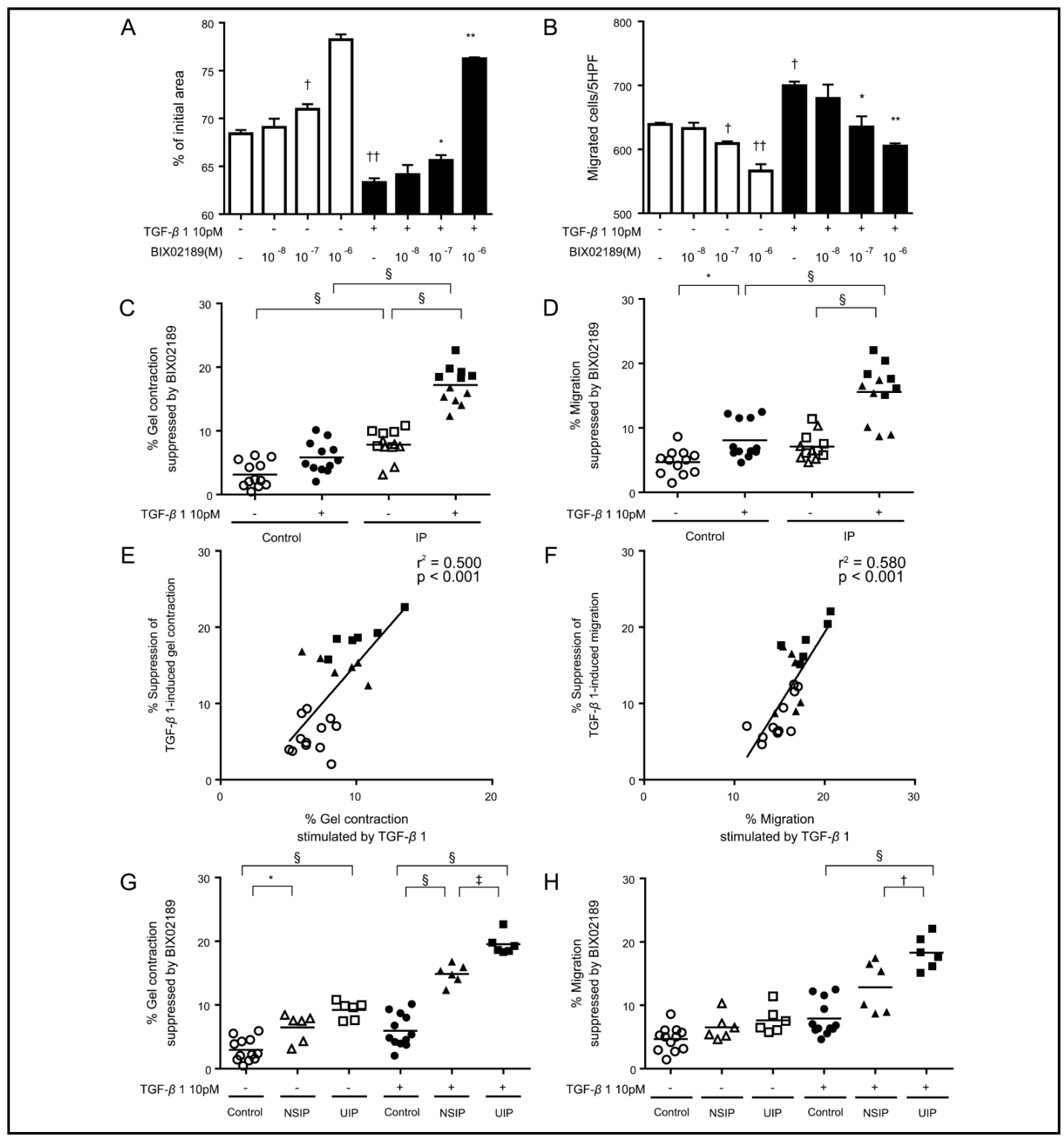

Fig. 2. Effect of extracellular-signal-regulated kinase 5 (ERK5) inhibitor, BIX02189, on collagen gel contraction and chemotaxis. (A, B) Effect of BIX02189 on HFL1-mediated gel contraction (A) and chemotaxis (B). Various concentrations of BIX02189 with or without transforming growth factor (TGF)- $\beta 1$ were assessed in the HLF1-mediated gel contraction and chemotaxis assays. The vertical axis in (A) shows the gel size on day 3, expressed as a percentage of the control. The vertical axis in (B) shows the number of migrated cells per five high-power fields (5HPF). (C, D) BIX02189 suppression of collagen gel contraction (C) and chemotaxis (D) in lung fibroblasts isolated from control and interstitial pneumonia (IP) subjects. The vertical axis in (C) shows the size of contracted gels following BIX02189 treatment for $72 \mathrm{~h}$, expressed as a percentage of the control. The vertical axis in (D) shows the number of migrated cells per five highpower fields (5HPF) following BIX02189 treatment for $8 \mathrm{~h}$, expressed as a percentage of the control. (E, F) Correlation between the magnitude of the TGF- $\beta 1$-induced increase in gel contraction and chemotaxis and degrees of suppression of TGF- $\beta 1$-mediated gel contraction and chemotaxis by BIX02189. Controls are represented by circles; closed triangles and squares indicate lung fibrosis subjects with histological nonspecific interstitial pneumonia and usual interstitial pneumonia patterns, respectively. Each symbol represents one patient. (G, H) Analysis of the IP group according to the histological pattern. The values represent the mean \pm SEM of at least three independent experiments. $(A, B){ }^{\dagger} \mathrm{P}<0.05,{ }^{\dagger} \mathrm{P}<0.001$, vs. solvent control; ${ }^{*} \mathrm{P}<0.05$, ${ }^{*} \mathrm{P}<0.001$ vs. stimulus. (C, D, G, H) ${ }^{*} \mathrm{P}<0.05,{ }^{\dagger} \mathrm{P}<0.01,{ }^{\circledR} \mathrm{P}<0.005,{ }^{\circledR} \mathrm{P}<0.001$. 


\section{Cellular Physiology Cell Physiol Biochem 2019;52:822-837 \\ \begin{tabular}{ll|l} 
and Biochemistry & $\begin{array}{l}\text { DOl: 10.33594/000000057 } \\
\text { Published online: } 5 \text { April 2019 }\end{array}$ & $\begin{array}{l}\text { O } 2019 \text { The Author(s). Published by } \\
\text { Cell Physiol Biochem Press GmbH\&Co. KG }\end{array}$ \\
\cline { 2 - 3 } &
\end{tabular} \\ Kadoya et al.: ERK5 Blockade Attenuates Lung Fibroblast Fibrotic Response}

TGF- $\beta 1: 9.7 \% \pm 2.0 \%$ in the lung fibrosis group vs. $7.1 \% \pm 1.6 \%$ in the control group; $\mathrm{P}$ $=0.003$ ) and chemotaxis ( $\%$ chemotaxis stimulated by TGF- $\beta 1$ : $17.2 \% \pm 1.9 \%$ in the lung fibrosis group vs. $14.9 \% \pm 1.7 \%$ in the control group; $\mathrm{P}=0.004$ ) in fibrotic fibroblasts when compared to normal fibroblasts (Fig. 1C, D).

\section{Response to ERK5 inhibitor}

We investigated whether ERK5 blockade altered the TGF- $\beta 1$-induced increase in collagen gel contraction and chemotaxis towards fibronectin in HFL1 cells. Pretreatment with the ERK5 inhibitor, BIX02189, reduced TGF- $\beta 1$-induced collagen gel contraction and chemotaxis in HFL1 cells in a concentration-dependent manner $(\mathrm{P}<0.05$ at concentrations of $10^{-7}$ to $10^{-6} \mathrm{M}$ BIX02189 \pm 10 pM TGF- $\beta 1$ vs. control; Fig. $\left.2 \mathrm{~A}, \mathrm{~B}\right)$. The inhibitory effect of BIX02189 on TGF- $\beta 1$-stimulated fibroblast activity was higher in fibroblasts from fibrotic lungs than in control fibroblasts ( $\mathrm{P}<0.001$, Fig. $2 \mathrm{C}$, D) and was positively correlated with the TGF- $\beta 1$-induced increase in collagen gel contraction and chemotaxis $\left(\mathrm{r}^{2}=0.500, \mathrm{P}<\right.$ 0.001 and $r^{2}=0.580, P<0.001$, respectively; Fig. $2 \mathrm{E}, \mathrm{F}$ ). Notably, the effect was greater in fibrotic lung fibroblasts from subjects with UIP than in those with NSIP $(P=0.003$ and 0.009 , respectively; Fig. 2G, H).

\section{Changes in TGF- $\beta 1$ target molecules in fibrotic lung fibroblasts}

Given that TGF- $\beta 1$ and BIX02189 regulate the contraction of collagen gels and chemotaxis to a greater extent in fibrotic lung fibroblasts than in control fibroblasts, we examined the expression of the TGF- $\beta 1$-dependent regulators $\alpha$-SMA and TGF- $\beta$ receptors (TGF- $\beta$ Rs) - which mediate myofibroblast differentiation - by western blotting. TGF- $\beta 1$ induced $\alpha$-SMA expression to a greater extent $(\mathrm{P}<0.001$, Fig. $3 \mathrm{~A})$ in fibrotic fibroblasts than in control fibroblasts $(2.8 \pm 0.8$ in the lung fibrosis group vs. $1.6 \pm 0.3$ in the control group; $\mathrm{P}<0.0001)$. Although there were changes in the relative increase of TGF- $\beta 1$-induced TGF- $\beta$ RI phosphorylation and total TGF- $\beta$ RI (TGF- $\beta$ RI) expression $(\mathrm{P}<0.05$ and $\mathrm{P}<0.001$, respectively; Fig. 3B, C), the differences between the groups were not statistically significant (TGF- $\beta$ RI phosphorylation: $1.4 \pm 0.5$ in the lung fibrosis group vs. $1.2 \pm 0.2$ in the control group; $\mathrm{P}=0.523$, and TGF- $\beta \mathrm{RI}$ : $2.7 \pm 1.3$ in the lung fibrosis group vs. $2.0 \pm 0.5$ in control group; $\mathrm{P}=0.196)$.

BIX02189 did not significantly suppress TGF- $\beta 1$-induced TGF- $\beta$ RI phosphorylation (Fig. 3B). There were changes in the relative decrease of TGF- $\beta$ RI following BIX02189 treatment $(\mathrm{P}<0.001$, Fig. $3 \mathrm{C})$ but the differences between groups were not statistically significant $(0.7$ \pm 0.2 in the lung fibrosis group vs. $0.6 \pm 0.2$ in the control group; $P=0.701 ;$ Fig. $3 \mathrm{C}$ ). TGF- $\beta$ RII expression in fibrotic fibroblasts was decreased by TGF- $\beta 1$ stimulation $(P=0.007$, Fig. 3D), whereas BIX02189 did not significantly alter TGF- $\beta 1$-induced TGF- $\beta$ RII expression.

TGF- $\beta 1$-induced fibronectin acts as an autocrine/paracrine factor that can potentially stimulate both collagen gel contraction and chemotaxis. To clarify the mechanistic basis for the observed effects, we measured fibronectin release, which was stimulated by TGF- $\beta 1$ and abolished by treatment with $10^{-6} \mathrm{M}$ BIX02189 (P < 0.001; Fig. 3E). The fold increase in fibronectin following TGF- $\beta 1$ stimulation (1.8 \pm 0.6 in the lung fibrosis group vs. $1.4 \pm 0.2$ in the control group; $\mathrm{P}=0.028)$ and fold reduction in the presence of BIX02189 (0.6 \pm 0.1 in the lung fibrosis group vs. $0.8 \pm 0.1$ in the control group; $\mathrm{P}=0.003$ ) were greater in fibroblasts from fibrotic lungs than in control fibroblasts.

\section{$B M P$ regulation in fibrotic lung fibroblasts}

Since members of the BMP family engage in crosstalk with the TGF- $\beta$ signaling pathway components and BMP receptors are expressed in human lung fibroblasts [8-10], we examined whether BMP-3 and -4 influence the TGF- $\beta 1$-mediated increase in collagen gel contraction and chemotaxis towards fibronectin in HFL1 cells. Exogenous BMP-3 and -4 reduced TGF- $\beta 1$-mediated chemotaxis towards fibronectin in a concentration-dependent manner $(\mathrm{P}<0.05$, Fig. 4B, D) and stimulated TGF- $\beta 1$-mediated collagen gel contraction $(\mathrm{P}<0.05$, Fig. 4A, C). These effects were more potent for BMP-3 than for BMP-4 (Fig. 4A-D). 
Fig. 3. Regulation of $\alpha$-SMA, transforming growth factor (TGF)- $\beta$ Receptors, and fibronectin in lung fibroblasts from control and interstitial pneumonia (IP) subjects.

Effect of TGF- $\beta 1$ and BIX02189 on $\alpha$-SMA (A), phospho-TGF$\beta R I \quad(B), \quad T G F-\beta R I$ (C), and TGF- $\beta$ RII (D) expression. Subconfluent fibroblasts were cultured in serum-free (SF)DMEM for $24 \mathrm{~h}$ and then incubated in the presence or absence of TGF- $\beta 1$ or BIX02189 for 8 h $(B, C)$ or $24 \mathrm{~h}(\mathrm{~A}$, D). Total protein was extracted, and western blotting was performed with specific antibodies against $\quad \alpha$-SMA, phospho-TGF- $\beta$ RI, TGF- $\beta$ RI, and TGF$\beta$ RII. The vertical axes show the relative intensity of $\alpha$-SMA, phospho-TGF- $\beta$ RI, TGF- $\beta$ RI, and TGF- $\beta$ RII vs. $\beta$-actin; the horizontal axes show the conditions. (E) Effect of BIX02189 on TGF- $\beta 1$-stimulated fibronectin production by lung fibroblasts. Sub-confluent fibroblasts were cultured in serum-free (SF)-DMEM for $2 \mathrm{~h}$ and incubated in the presence or absence of TGF- $\beta 1$ or BIX02189 for $24 \mathrm{~h}$. The supernatant was harvested, and fibronectin level was quantified. The vertical axis shows fibronectin production, expressed as amount per $10^{5} \mathrm{cells} / \mathrm{ml}$; the horizontal axis shows the conditions. The values represent mean \pm SEM of at least three independent experiments. (A-E) ${ }^{*} \mathrm{P}<0.05,{ }^{\dagger} \mathrm{P}<0.01,{ }^{\S} \mathrm{P}<0.001$.

The TGF- $\beta 1$-mediated suppression of BMP-4 expression was significant in fibroblasts from fibrotic lungs $(\mathrm{P}=0.007$; Fig. 4E), whereas treatment with BIX02189 did not significantly alter TGF- $\beta 1$-mediated regulation of BMP-3 and -4 (Fig. 4E, F). Additionally, there were no changes in the levels of the BMP antagonists Gremlin1 and 2 (data not shown) [9-10] [25].

\section{Effects of ERK5 inhibitor on TGF- $\beta 1$ signaling in fibrotic lung fibroblasts}

Given that the activation of Smad3 signaling in response to TGF- $\beta$ treatment enhances $\alpha$-SMA expression, gel contraction, and fibronectin production in fibroblasts [26], we examined the phosphorylation status of Smad3. The relative increase in phosphorylated (p)-Smad3/ total (t)-Smad3 upon TGF- $\beta 1$ stimulation was significantly higher in fibrotic fibroblasts than in control fibroblasts $(4.1 \pm 1.4$ in the lung fibrosis group vs. $1.5 \pm 0.4$ in the 


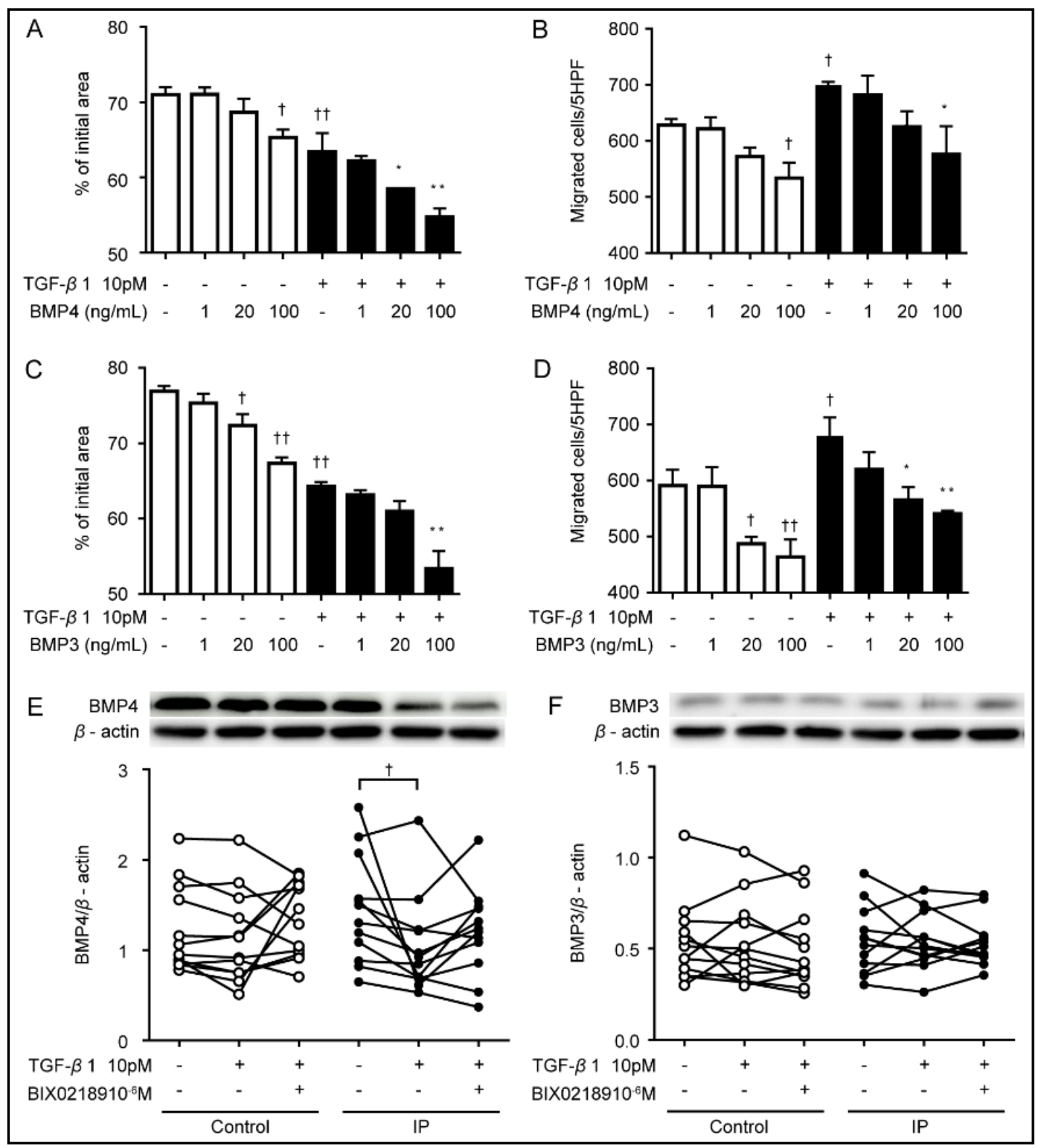

Fig. 4. Effects of BMP-3 and -4 on chemotaxis and gel contraction and BMP- 3 and -4 regulation in fibroblasts from control and lung fibrotic (interstitial pneumonia, IP) subjects. (A-D) Effect of various concentrations of BMP-3 and -4 in the presence or absence of transforming growth factor (TGF)- $\beta 1$ on HLF1-mediated gel contraction (A, C) and chemotaxis (B, D). The vertical axes in (A) and (C) show gel size on day 3, expressed as a percentage of the control. The vertical axes in (B) and (D) show the number of migrated cells per five high-power fields (5HPF). (E, F) Effect of BIX02189 on TGF- $\beta 1$-induced BMP-3 and -4 expression. Subconfluent fibroblasts were cultured in serum-free (SF)-DMEM for $24 \mathrm{~h}$, and then incubated with or without TGF- $\beta 1$ or BIX02189 for $8 \mathrm{~h}$. Total protein was then extracted, and western blotting was performed with antibodies against BMP-3 and -4. The vertical axes in (E) and (F) show the relative intensity of BMP-3 or -4 vs. $\beta$-actin ratio; the horizontal axes show the conditions. The values represent mean \pm SEM of at least three independent experiments. For (A-D), ${ }^{+} \mathrm{P}<0.05,{ }^{+} \mathrm{P}<0.01$ vs. solvent control; ${ }^{*} \mathrm{P}<0.05,{ }^{* *} \mathrm{P}<0.01$ vs. with stimulus. For $(\mathrm{E}, \mathrm{F}),{ }^{\dagger} \mathrm{P}<0.01$. 


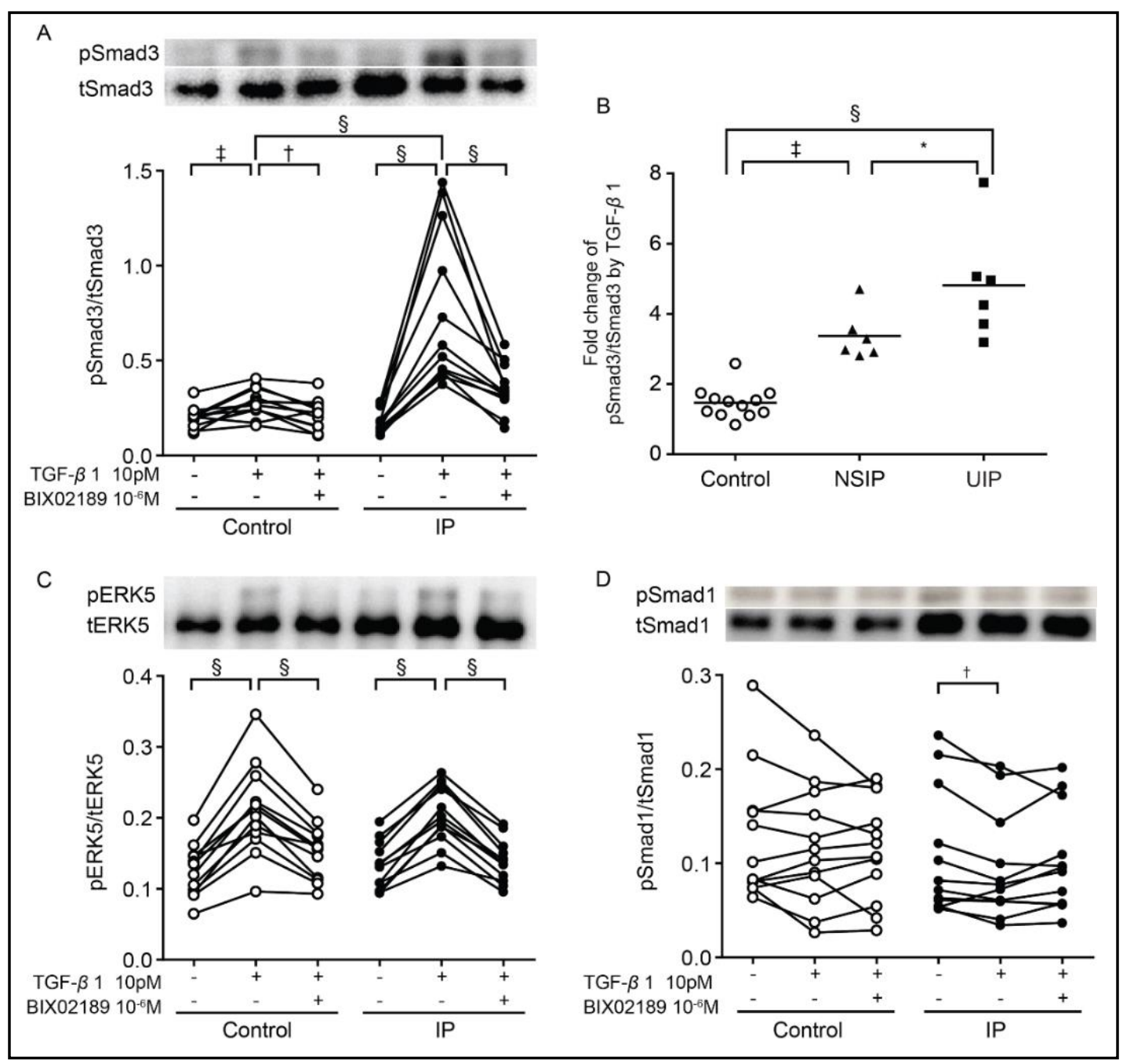

Fig. 5. Regulation of transforming growth factor (TGF)- $\beta 1$ signaling in lung fibroblasts from control and lung fibrotic (interstitial pneumonia, IP) subjects. (A, C, D) Effect of BIX02189 on TGF- $\beta 1$-induced Smad3 (A), extracellular-signal-regulated kinase (ERK)5 (C), and Smad1 (D) phosphorylation. Sub-confluent fibroblasts were cultured in serum-free (SF)-DMEM for $24 \mathrm{~h}$ and then incubated in the presence or absence of TGF- $\beta 1$ or BIX02189 for $8 \mathrm{~h}$. Total protein was extracted, and western blotting was performed with specific antibodies against phospho-Smad3 (pSmad3), Smad3 (tSmad3), ERK5 (tERK5), phospho-Smad1 (pSmad1), and Smad1 (tSmad1). Phospho-ERK5 (pERK5) can be detected as a band with slower electrical migration that represents the active form of the protein [1]. The vertical axes show the relative ratio of phosphoSmad3 to total Smad3, phospho-ERK5 to total ERK5, or phospho-Smad1 to total Smad1; the horizontal axes show the conditions. (B) Relative increases in Smad3 phosphorylation in the control, nonspecific interstitial pneumonia, and usual interstitial pneumonia groups after TGF- $\beta 1$ stimulation. The vertical axis shows the ratio of fold increase in phospho-Smad3 to total Smad3. The values represent mean \pm SEM of at least three independent experiments. ${ }^{*} \mathrm{P}<0.05,{ }^{\dagger} \mathrm{P}<0.01{ }^{\ddagger} \mathrm{P}<0.005,{ }^{\circledR} \mathrm{P}<0.001(\mathrm{~A}-\mathrm{D})$.

control group; $\mathrm{P}=0.0001$; Fig. $5 \mathrm{~A}$ ) and in fibrotic lung fibroblasts from subjects with UIP than in those from subjects with NSIP ( $\mathrm{P}=0.0363$; Fig. 5B).

The relative decrease in TGF- $\beta 1$-induced $\mathrm{p}-\mathrm{Smad} 3 / \mathrm{t}$-Smad3 in the presence of BIX02189 was more significant in fibrotic fibroblasts than in control fibroblasts (control: $\mathrm{P}=0.0093$ vs. lung fibrosis: $\mathrm{P}=0.0005$; Fig. $5 \mathrm{~A}$ ). Although the differences of the relative increase in TGF$\beta 1$-induced p-ERK5/t-ERK5 and the corresponding decrease following BIX02189 treatment, between the groups were not statistically significant (control: $\mathrm{P}=0.0005$ vs. lung fibrosis: 


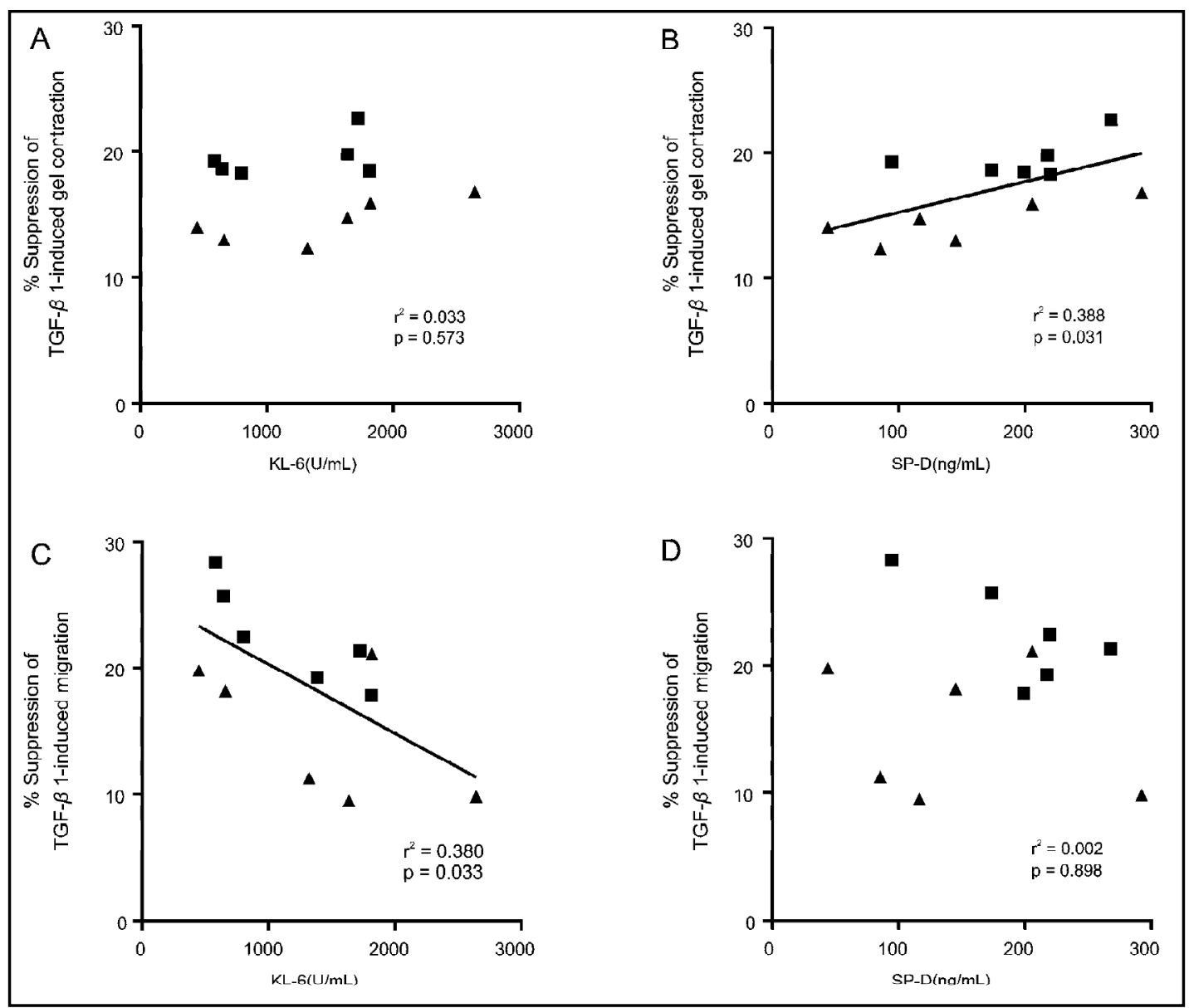

Fig. 6. Relationship between the extracellular-signal-regulated kinase (ERK)5 inhibitor response to TGF$\beta 1$-stimulated fibroblast bioactivity in vitro and biomarkers of lung fibrosis. (A-D) Comparison of the relationships between suppression of TGF- $\beta 1$-induced gel contraction by BIX02189 and serum KL-6 (A) and SP-D (B) levels; and TGF- $\beta 1$-induced migration and KL-6 (C) and SP-D (D) levels. Closed triangles and squares indicate lung fibrosis subjects with nonspecific interstitial pneumonia, and usual interstitial pneumonia patterns, respectively. Each symbol represents one patient.

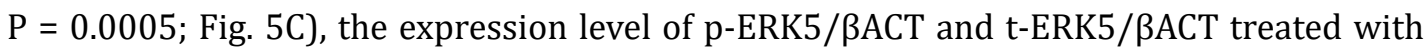
TGF- $\beta 1$ was higher in fibrotic fibroblasts than in control fibroblasts, when the expression level of p-ERK5 and t-ERK5 were analyzed separately $(\mathrm{P}=0.0441$ and 0.0297 , respectively; Fig. S1A, B - all supplementary material available online at www.cellphysiolbiochem.com). The relative decrease in Smad1 phosphorylation - as evidenced by the inhibition of BMP signaling in response to TGF- $\beta 1$ stimulation - was significant in fibroblasts from fibrotic lungs $(\mathrm{P}=0.0093$; Fig. 5D). However, BIX02189 did not restore the TGF- $\beta 1$-suppressed Smad1 phosphorylation in fibrotic lung fibroblasts (Fig. 5D).

\section{Bioinformatic analysis of fibrotic fibroblast phenotypes}

To quantify the activity of individual promoters across the genome, we applied CAGE to 20 samples (7 from normal and 13 from fibrotic fibroblast samples; the latter included seven UIP and six NSIP fibroblast samples). We also identified DEGs with altered promoter activity in fibrotic vs. normal fibroblasts. Our analysis (FDR < 5\%; Fig. S2A) yielded 223 upregulated (Table S1A) and 56 downregulated (Table S1B) genes. A Reactome analysis showed that upregulated DEGs were significantly enriched in fibrosis-related processes, including interleukin-4 and -13 signaling, extracellular matrix organization, elastic fiber formation, molecules associated with elastic fibers, MET-activated protein tyrosine kinase 2 
Table 2. Reactome pathway enrichment analysis of 223 genes upregulated in fibrotic fibroblasts when compared to control fibroblasts (FDR < 0.05). Abbreviations: DEG, differentially expressed gene; FDR, false discovery rate; PTK2, protein tyrosine kinase 2

\begin{tabular}{|c|c|c|}
\hline Pathway name & Entities FDR & DEG \\
\hline $\begin{array}{l}\text { Interleukin-4 and -13 } \\
\text { signaling }\end{array}$ & 0.00152696 & CDKN1A; CCND1; MMP2; HGF; CCL2; CD36; BCL2L1; ICAM1 \\
\hline $\begin{array}{l}\text { Extracellular matrix } \\
\text { organization }\end{array}$ & 0.00152696 & $\begin{array}{c}\text { FBN2; MME; LAMA1; LAMA4; MMP2; COL11A1; LAMA3; FBLN1; } \\
\text { PLOD2; FBLN2; FBLN5; ICAM1; MFAP5; LOX; CTSL; CTSK; } \\
\text { MFAP2; A2M; ADAMTS8 }\end{array}$ \\
\hline Elastic fiber formation & 0.006061572 & FBN2; MFAP5; LOX; MFAP2; FBLN1; FBLN2; FBLN5 \\
\hline $\begin{array}{l}\text { Molecules associated } \\
\text { with elastic fibers }\end{array}$ & 0.013795945 & FBN2; MFAP5; MFAP2; FBLN1; FBLN2; FBLN5 \\
\hline $\begin{array}{l}\text { MET activates PTK2 } \\
\text { signaling }\end{array}$ & 0.031930241 & LAMA1; LAMA4; HGF; COL11A1; LAMA3 \\
\hline $\begin{array}{l}\text { Degradation of the } \\
\text { extracellular matrix }\end{array}$ & 0.040522002 & $\begin{array}{l}\text { FBN2; MME; CTSL; CTSK; MMP2; COL11A1; LAMA3; A2M; } \\
\text { ADMATS8 }\end{array}$ \\
\hline
\end{tabular}

signaling, and extracellular matrix degradation (FDR $<0.05$; Table 2). These results indicated that fibrotic fibroblasts are likely controlled by transcriptional regulatory networks that are distinct from those of normal fibroblasts.

We speculated that molecular interactions between the TGF- $\beta 1$ and ERK5 signaling networks contribute to the sensitivity of fibrotic fibroblasts to TGF- $\beta 1$. To examine this possibility, we constructed DEG interaction networks using VaProS software and identified a key upregulated gene in fibrotic fibroblasts (Fig. S2A), fibulin-5 (FBLN5). Although FBLN5 was not specific to either UIP or NSIP (Table S2), it was closely associated with the ERK5 (MAPK7)-TGF- $\beta 1$-regulated Smad3, $\alpha$-SMA (ACTA2), and fibronectin (FN1) networks in our analysis (Fig. S2B-D) and was enriched in the elastic fiber formation, molecules associated with elastic fibers, and ECM organization categories (Table 2).

Baseline and TGF- $\beta 1$-induced fibulin- 5 protein levels were higher in fibrotic lung fibroblasts than in control fibroblasts (baseline: $\mathrm{P}=0.033$ and TGF- $\beta 1$-treated: $\mathrm{P}<0.001$; Fig. S2E). However, no association with the BMP4-ERK5 (MAPK7) network was detected by the VaProS software analysis (data not shown) as suggested BIX02189 did not affect BMP4-related Smad1 activation (Fig. 5D). These results further support that BMP4 has no dominant role in ERK5-mediated fibrotic process signaling in fibrotic fibroblasts. Also, we did not identify any molecular interactions between ERK5 and TGF- $\beta$ Rs.

\section{Blockade of ERK5-mediated lung fibroblast regulation}

To investigate the direct functional roles of ERK5-mediated lung fibroblasts activities, we downregulated ERK5 by siRNA in HFL-1 cells. Transfection with ERK5 siRNA led to a complete reversal of targets which suggested molecular interaction by the Vapros analysis (Fig. S2B-D). Smad3 phosphorylation and $\alpha$-SMA, fibronectin, and fibulin-5 expression were affected by ERK5 siRNA transfection (Fig. S3A), whereas, TGF- $\beta$ RI phosphorylation and the amount of TGF- $\beta$ RI and II were not affected. Furthermore, ERK5 downregulation attenuated gel contraction and chemotaxis (Fig. S3B, C).

\section{Effects of ERK5 inhibition on TGF- $\beta 1$-stimulated fibroblast activity in vitro and biomarkers} for lung fibrosis

Given our observation that ERK5 inhibition in fibrotic lung fibroblasts enhanced their sensitivity to TGF- $\beta 1$-induced fibrosis in contrast to normal fibroblasts, we investigated whether our ex-vivo data had clinical significance. To this end, we measured the serum levels of the lung fibrosis biomarkers KL-6 and SP-D in patients with lung fibrosis at the time of 


\section{Cellular Physiology Cell Physiol Biochem 2019;52:822-837 \\ \begin{tabular}{ll|l} 
and Biochemistry & $\begin{array}{l}\text { DOl: 10.33594/000000057 } \\
\text { Published online: } 5 \text { April 2019 }\end{array}$ & $\begin{array}{l}\text { O } 2019 \text { The Author(s). Published by } \\
\text { Cell Physiol Biochem Press GmbH\&Co. KG }\end{array}$ \\
\cline { 2 - 3 } &
\end{tabular} \\ Kadoya et al.: ERK5 Blockade Attenuates Lung Fibroblast Fibrotic Response}

primary lung fibroblast sample collection. The ability of BIX02189 to abrogate the TGF$\beta 1$-induced increase in collagen gel contraction was positively correlated with SP-D $\left(\mathrm{r}^{2}=\right.$ 0.388: $\mathrm{P}=0.031$, Fig. $6 \mathrm{~B}$ ) but not KL-6 (Fig. $6 \mathrm{~A}$ ) levels. In contrast, the inhibitory effects of BIX02189 on TGF- $\beta 1$-induced migration were negatively correlated with KL- $6\left(\mathrm{r}^{2}=0.380\right.$ : $\mathrm{P}=0.033$, Fig. 6C) but not SP-D (Fig. 6D) levels. None of the other clinical, histopathological, spirometric parameters such as the sustainer and rapid decliner categories according to FVC reduction rate were related to in vitro fibroblast responses to ERK5 inhibitor treatment or to ex vivo fibroblast activity.

\section{Discussion}

In this study, we evaluated the phenotypic differences between distinct fibrotic fibroblast subtypes and performed a series of bioinformatic analyses on DEGs. The most notable feature of fibrotic lung fibroblasts was their increased bioactivity following activation of the canonical TGF- $\beta 1 /$ Smad3 pathway which upregulated ERK5 phosphorylation and further led to TGF- $\beta 1$-induced collagen gel contraction and migration. These effects were attenuated by treatment with ERK5 inhibitor, BIX02189, and were more potent in fibroblasts from UIP than from NSIP patients.

These phenotypic differences are in accordance with previous reports that TGF- $\beta$ is more expressed in lung tissues from IPF/UIP than in those from NSIP [9-10] [27]. We also identified specific characteristics of fibrotic lung fibroblasts, including increased TGF$\beta 1$-induced $\alpha$-SMA expression, Smad3 phosphorylation, fibronectin release, and ERK5 phosphorylation when compared to normal lung fibroblasts. There were no statistically significant differences in the relative regulation of TGF- $\beta 1$-mediated TGF- $\beta$ RI activation and TGF- $\beta$ Rs amount following BIX02189 treatment between the groups. We demonstrated that BIX02189 suppressed TGF- $\beta 1$-induced TGF- $\beta$ RI but not by the genetic inhibition of ERK5 as previously described [28].

Bioinformatics analyses of DEGs identified fibulin- 5 as a novel candidate factor in the crosstalk between the ERK5 and TGF- $\beta 1$ signaling pathways that was induced by TGF- $\beta 1$ treatment. Fibulin-5 - an elastin-binding protein - was upregulated in hepatic fibrosis and in the fibrotic skin of patients with systemic scleroderma, which is considered a biomarker for elastogenesis in lung tissues with COPD [29-31]. Fibulin-5, which is induced via canonical TGF- $\beta 1 /$ Smad signaling in human lung fibroblasts, was shown to exert profibrotic effects [32] and induce skin fibrosis in part by activating dermal fibroblasts and stimulating the proliferation and migration of smooth muscle cells in the airways [31] [33-34]. Additionally, blockade of ERK5 did not only suppressed Smad3, $\alpha$-SMA, and fibronectin - detected in the ERK5 (MAPK7) networks by VaProS analysis; but also gel contraction and migration as well as fibulin-5 expression. We detected no association between the BMPs or TGF- $\beta$ Rs -ERK5 networks in the molecular interaction analysis. This suggests that TGF- $\beta 1$-ERK5 interaction plays a critical role in fibrotic fibroblast-mediated lung fibrosis processes.

The results of this study demonstrate that both BMP- 3 and -4 suppressed the migration of lung fibroblasts towards fibronectin but enhanced the TGF- $\beta 1$-induced increase in gel contraction. These diverse effects are supported by a previous report showing that BMP4 inhibited TGF- $\beta 1$-induced synthesis of ECM components including fibronectin while promoting $\alpha$-SMA expression, which was responsible for increased gel contraction [9-10] [27]. BMPs do not affect the activity of reporter genes regulated by the TGF- $\beta 1$-induced Smad-binding element in human lung fibroblasts [9].

However, we showed that TGF- $\beta 1$ suppressed the BMP-4/Smad1 signaling pathway, whereas the ERK5 inhibitor did not relieve this suppression in fibrotic lung fibroblasts. These results suggest that BMPs may at least partly inhibit fibroblast migration independent of TGF- $\beta 1$-induced ERK5 signaling. The levels of the BMP antagonists Gremlin1 and 2, which were previously implicated in the development of lung fibrosis [9-10] [25], were unchanged in the present study. These results may suggest that the different phenotypes 


\section{Cellular Physiology Cell Physiol Biochem 2019;52:822-837 \\ \begin{tabular}{ll|l} 
and Biochemistry & $\begin{array}{l}\text { DOl: 10.33594/000000057 } \\
\text { Published online: } 5 \text { April 2019 }\end{array}$ & $\begin{array}{l}\text { O } 2019 \text { The Author(s). Published by } \\
\text { Cell Physiol Biochem Press GmbH\&Co. KG }\end{array}$ \\
\cline { 2 - 3 } & Kar
\end{tabular} \\ Kadoya et al.: ERK5 Blockade Attenuates Lung Fibroblast Fibrotic Response}

of sensitive responses to TGF- $\beta 1$ in fibrotic fibroblasts may arise from the activation of the ERK5-FBLN5-Smad3 cascade rather than the TGF- $\beta$ Rs and BMPs signal regulation in fibrotic fibroblast-mediated lung fibrosis processes. In other words, these processes may be caused by the sustained exposure to autocrine/paracrine TGF- $\beta 1$ signals during lung inflammation and then may result in the transition from the parenchymal lung fibroblasts to the fibrotic fibroblast phenotype.

Serum SP-D and KL-6 levels are clinical surrogate markers in IPF patients treated with pirfenidone [30] [35]. SP-D suppressed lung fibrosis by inhibiting macrophage infiltration and TGF- $\beta 1$ release [36]; in contrast, KL- 6 promoted alveolar inflammation with increased TGF- $\beta 1$ release in mouse lungs treated with bleomycin [37] and enhanced the stimulatory effects of fibronectin on human lung fibroblast chemotaxis and myofibroblast differentiation [38-39]. In the present study, higher SP-D and lower KL-6 levels were associated with increased sensitivity to ERK5 inhibitor and suppression of TGF- $\beta 1$-stimulated lung fibroblast bioactivity ex vivo, suggesting that serum SP-D and KL-6 can serve as markers for epithelialmesenchymal interactions and can identify patients with lung fibrosis who are candidates for anti-fibrotic treatment with ERK5 inhibitors.

\section{Conclusion}

In conclusion, the results presented here provide evidence of the high sensitivity of fibrotic fibroblasts to the canonical TGF- $\beta 1 / \operatorname{Smad} 3$ signaling pathway, which mediates fibrotic processes that can be suppressed by ERK5 inhibitor treatment; this extends our previous findings that ERK5 inhibitor suppressed airway fibrosis in COPD lung fibroblasts [12]. The screened genes and TGF- $\beta 1$-ERK5 interaction analysis provide detailed insights into the molecular mechanism underlying the progression of lung fibrosis mediated by fibrotic fibroblasts. Although our study had some limitations such as the fact that we did not test whether the ERK5 inhibitor reverses lung fibrosis in tissues and the limited number of fibroblast lines that were used, our findings shed light on the pathogenesis of lung fibrosis and provide preliminary evidence suggesting that ERK5 and fibulin-5 are potential therapeutic targets.

\section{Acknowledgements}

We thank X. Liu, F. Sakai, T. Takemura, T. Iwasawa, I. Taki, L. Ning, N. Okamoto, T. Ito, S Kusano, A Kusano, R. Mineki, and E. Kobayashi for their technical assistance and advice.

Written informed consents were obtained from all subjects who participated in this study. All experiments were approved by the ethics committee of Juntendo University School of Medicine and Kanagawa Cardiovascular and Respiratory Center (approval no. 2012173).

This research was partially supported by the Platform Project for Supporting Drug Discovery and Life Science Research from AMED (grant no. JP16am0101057).

KK was responsible for cell culture, biochemical studies, interpretation of results, and manuscript writing. ST designed the study and wrote the manuscript. ST, MT, YN, YK, TOkabe, $\mathrm{NK}, \mathrm{KI}$, and KT provided technical advice and assisted in the interpretation of results. TT and NK contributed to biochemical studies and manuscript writing. ST, HK, and TOgura recruited the patients and obtained their written, informed consent. MT, MI, JW, and JJ prepared the rat tail tendon collagen. All authors critically reviewed and contributed to the final manuscript.

\section{Disclosure Statement}

The authors declare that they have no conflict of interests. 


\section{Cellular Physiology Cell Physiol Biochem 2019;52:822-837 \begin{tabular}{l|l|l|l} 
DOl: 10.33594/000000057 & ( 2019 The Author(s). Published by \\
\hline
\end{tabular} and BIOChemistry Published online: 5 April $2019 \quad$ Cell Physiol Biochem Press GmbH\&Co. KG \\ Kadoya et al.: ERK5 Blockade Attenuates Lung Fibroblast Fibrotic Response}

\section{References}

- 1 Garcia-Hoz C, Sanchez-Fernandez G, Diaz-Meco MT, Moscat J, Mayor F, Ribas C: G alpha(q) acts as an adaptor protein in protein kinase $\mathrm{C}$ zeta (PKCzeta)-mediated ERK5 activation by G protein-coupled receptors (GPCR). J Biol Chem 2010;285:13480-13489.

- 2 Scotton CJ, Chambers RC: Molecular targets in pulmonary fibrosis: the myofibroblast in focus. Chest 2007;132:1311-1321.

- 3 Lee CG, Cho SJ, Kang MJ, Chapoval SP, Lee PJ, Noble PW, Yehualaeshet T, Lu B, Flavell RA, Milbrandt J, Homer RJ, Elias JA: Early growth response gene 1-mediated apoptosis is essential for transforming growth factor beta1-induced pulmonary fibrosis. J Exp Med 2004;200:377-389.

- 4 Bartram U, Speer CP: The role of transforming growth factor beta in lung development and disease. Chest 2004;125:754-765.

5 Biernacka A, Dobaczewski M, Frangogiannis NG: TGF- $\beta$ signaling in fibrosis. Growth Factors 2011;29:196202.

6 Kamio K, Liu X, Sugiura H, Togo S, Kobayashi T, Kawasaki S, Wang X, Mao L, Ahn Y, Hogaboam C, Toews ML, Rennard SI: Prostacyclin analogs inhibit fibroblast contraction of collagen gels through the cAMP-PKA pathway. Am J Respir Cell Mol Biol 2007;37:113-120.

- 7 Togo S, Liu X, Wang X, Sugiura H, Kamio K, Kawasaki S, Kobayashi T, Ertl RF, Ahn Y, Holz O, Magnussen H, Fredriksson K, Skold CM, Rennard SI: PDE4 inhibitors roflumilast and rolipram augment PGE2 inhibition of TGF-\{beta\}1-stimulated fibroblasts. Am J Physiol Lung Cell Mol Physiol 2009;296:L959-L969.

- 8 Verhamme FM, Bracke KR, Joos GF, Brusselle GG: Transforming growth factor-beta superfamily in obstructive lung diseases. more suspects than TGF-beta alone. Am J Respir Cell Mol Biol 2015;52:653-662.

- 9 Pegorier S, Campbell GA, Kay AB, Lloyd CM: Bone morphogenetic protein (BMP)-4 and BMP-7 regulate differentially transforming growth factor (TGF)-beta1 in normal human lung fibroblasts (NHLF). Respir Res 2010;11:85.

- 10 Yu X, Gu P, Huang Z, Fang X, Jiang Y, Luo Q, Li X, Zhu X, Zhan M, Wang J, Fan L, Chen R, Yu J, Gu Y, Liang A, Yi X: Reduced expression of BMP3 contributes to the development of pulmonary fibrosis and predicts the unfavorable prognosis in IIP patients. Oncotarget 2017;8:80531-80544.

- 11 Kim S, Lim JH, Woo CH: ERK5 inhibition ameliorates pulmonary fibrosis via regulating Smad3 acetylation. Am J Pathol 2013;183:1758-1768.

12 Namba Y, Togo S, Tulafu M, Kadoya K, Nagahama KY, Taka H, Kaga N, Orimo A, Liu X, Takahashi K: Combination of glycopyrronium and indacaterol inhibits carbachol-induced ERK5 signal in fibrotic processes. Respir Res 2017;18:46.

- 13 Elsdale T, Bard J: Collagen substrata for studies on cell behavior. J Cell Biol 1972;54:626-637.

- 14 Holz O, Zuhlke I, Jaksztat E, Muller KC, Welker L, Nakashima M, Diemel KD, Branscheid D, Magnussen H, Jörres RA: Lung fibroblasts from patients with emphysema show a reduced proliferation rate in culture. Eur Respir J 2004;24:575-579.

- 15 Chung JH, Lynch DA: The value of a multidisciplinary approach to the diagnosis of usual interstitial pneumonitis and idiopathic pulmonary fibrosis: radiology, pathology, and clinical correlation. AJR Am J Roentgenol 2016;206:463-471.

- 16 Mio T, Adachi Y, Romberger DJ, Ertl RF, Rennard SI: Regulation of fibroblast proliferation in threedimensional collagen gel matrix. In vitro Cell Dev Biol Anim 1996;32:427-433.

- 17 Murata M, Nishiyori-Sueki H, Kojima-Ishiyama M, Carninci P, Hayashizaki Y, Itoh M: Detecting expressed genes using CAGE. Methods Mol Biol 2014;1164:67-85.

18 Kim D, Pertea G, Trapnell C, Pimentel H, Kelley R, Salzberg SL: TopHat2: accurate alignment of transcriptomes in the presence of insertions, deletions and gene fusions. Genome Biol 2013;14:R36.

19 Trapnell C, Hendrickson DG, Sauvageau M, Goff L, Rinn JL, Pachter L: Differential analysis of gene regulation at transcript resolution with RNA-seq. Nat Biotechnol 2013;31:46-53.

20 Kinjo S, Monma N, Misu S, Kitamura N, Imoto J, Yoshitake K, Gojobori T, Ikeo K: Maser: one-stop platform for NGS big data from analysis to visualization. Database (Oxford) 2018;2018:bay027.

- 21 Fabregat A, Sidiropoulos K, Garapati P, Gillespie M, Hausmann K, Haw R, Jassal B, Jupe S, Korninger F, McKay S, Matthews L, May B, Milacic M, Rothfels K, Shamovsky V, Webber M, Weiser J, Williams M, Wu G, Stein L, et al.: The Reactome pathway Knowledgebase. Nucleic Acids Res 2018;46:D649-D655. 


\section{Cellular Physiology Cell Physiol Biochem 2019;52:822-837 \begin{tabular}{c|c|c|} 
DOl: 10.33594/000000057 & O 2019 The Author(s). Published by \\
and Biochemistry
\end{tabular} \\ \begin{tabular}{l|l} 
Published online: 5 April 2019 & Cell Physiol Biochem Press GmbH\&Co. KG \\
\hline
\end{tabular} \\ Kadoya et al.: ERK5 Blockade Attenuates Lung Fibroblast Fibrotic Response}

22 Gojobori T, Ikeo K, Katayama Y, Kawabata T, Kinjo AR, Kinoshita K, Kwon Y, Migita O, Mizutani H, Muraoka M, Nagata K, Omori S, Sugawara H, Yamada D, Yura K: VaProS: a database-integration approach for protein/ genome information retrieval. J Struct Funct Genomics 2016;17:69-81.

- 23 Shannon P, Markiel A, Ozier O, Baliga NS, Wang JT, Ramage D, Amin N, Schwikowski B, Ideker T: Cytoscape: a software environment for integrated models of biomolecular interaction networks. Genome Res 2003;13:2498-2504.

24 Benjamini Y, Hochberg Y: Controlling the false discovery rate: a practical and powerful approach to multiple testing. J R Statist Soc B 1995;57:289-300.

25 Myllarniemi M, Lindholm P, Ryynanen MJ, Kliment CR, Salmenkivi K, Keski-Oja J, Kinnula VL, Oury TD, Koli $\mathrm{K}$ : Gremlin-mediated decrease in bone morphogenetic protein signaling promotes pulmonary fibrosis. Am J Respir Crit Care Med 2008;177:321-329.

26 Kobayashi T, Liu X, Wen FQ Kohyama T, Shen L, Wang XQ Hashimoto M, Mao L, Togo S, Kawasaki S, Sugiura H, Kamio K, Rennard SI: Smad3 mediates TGF-beta1-induced collagen gel contraction by human lung fibroblasts. Biochem Biophys Res Commun 2006;339:290-295.

27 Jeffery TK, Upton PD, Trembath RC, Morrell NW: BMP4 inhibits proliferation and promotes myocyte differentiation of lung fibroblasts via Smad1 and JNK pathways. Am J Physiol Lung Cell Mol Physiol 2005;288:L370-L378.

28 Park SJ, Choi YS, Lee S, Lee YJ, Hong S, Han S, Kim BC: BIX02189 inhibits TGF-beta1-induced lung cancer cell metastasis by directly targeting TGF-beta type I receptor. Cancer Lett 2016;381:314-322.

29 Bracht T, Schweinsberg V, Trippler M, Kohl M, Ahrens M, Padden J, Naboulsi W, Barkovits K, Megger DA, Eisenacher M, Borchers CH, Schlaak JF, Hoffmann AC, Weber F, Baba HA, Meyer HE, Sitek B: Analysis of disease-associated protein expression using quantitative proteomics-fibulin- 5 is expressed in association with hepatic fibrosis. J Proteome Res 2015;14:2278-2286.

30 Ley B, Brown KK, Collard HR: Molecular biomarkers in idiopathic pulmonary fibrosis. Am J Physiol Lung Cell Mol Physiol 2014;307:L681-L691.

31 Fu J, Zheng M, Zhang X, Zhang Y, Chen Y, Li H, Wang X, Zhang J: Fibulin-5 promotes airway smooth muscle cell proliferation and migration via modulating Hippo-YAP/TAZ pathway. Biochem Biophys Res Commun 2017;493:985-991.

32 Kuang PP, Joyce-Brady M, Zhang XH, Jean JC, Goldstein RH: Fibulin-5 gene expression in human lung fibroblasts is regulated by TGF-beta and phosphatidylinositol 3-kinase activity. Am J Physiol Cell Physiol 2006;291:C1412-C1421.

33 Nakasaki M, Hwang Y, Xie Y, Kataria S, Gund R, Hajam EY, Samuel R, George R, Danda D, M JP, Nakamura T, Shen Z, Briggs S, Varghese S, Jamora C: The matrix protein Fibulin-5 is at the interface of tissue stiffness and inflammation in fibrosis. Nat Commun 2015;6:8574.

34 Yanagisawa H, Davis EC, Starcher BC, Ouchi T, Yanagisawa M, Richardson JA, Olson EN: Fibulin-5 is an elastin-binding protein essential for elastic fibre development in vivo. Nature 2002;415:168-171.

35 Ikeda K, Shiratori M, Chiba H, Nishikiori H, Yokoo K, Saito A, Hasegawa Y, Kuronuma K, Otsuka M, Yamada G, Takahashi H: Serum surfactant protein D predicts the outcome of patients with idiopathic pulmonary fibrosis treated with pirfenidone. Respir Med 2017;131:184-191.

36 Aono Y, Ledford JG, Mukherjee S, Ogawa H, Nishioka Y, Sone S, Beers MF, Noble PW, Wright JR: Surfactant protein-D regulates effector cell function and fibrotic lung remodeling in response to bleomycin injury. Am J Respir Crit Care Med 2012;185:525-536.

37 Xu L, Yang D, Zhu S, Gu J, Ding F, Bian W, Rong Z, Shen C: Bleomycin-induced pulmonary fibrosis is attenuated by an antibody against KL-6. Exp Lung Res 2013;39:241-248.

38 Hirasawa Y, Kohno N, Yokoyama A, Inoue Y, Abe M, Hiwada K: KL-6, a human MUC1 mucin, is chemotactic for human fibroblasts. Am J Respir Cell Mol Biol 1997;17:501-507.

39 Xu L, Yan DR, Zhu SL, Gu J, Bian W, Rong ZH, Shen C: KL-6 regulated the expression of HGF, collagen and myofibroblast differentiation. Eur Rev Med Pharmacol Sci 2013;17:3073-3077. 